\title{
SEISMIC ANALYSIS OF HIGH DAMPING RUBBER BEARINGS FOR
}

\section{BASE ISOLATION}

\author{
G. Arya ${ }^{1}$, Alice T.V ${ }^{2}$, Alice Mathai ${ }^{3}$ \\ ${ }^{1}$ Student, Department of Civil Engineering, Mar Athanasius College of Engineering, Kerala, India \\ ${ }^{2}$ Professor, Department of Civil Engineering, Mar Athanasius College of Engineering, Kerala, India \\ ${ }^{3}$ Professor, Department of Civil Engineering, Mar Athanasius College of Engineering, Kerala, India
}

\begin{abstract}
Base isolation is a mechanism that provides earthquake resistance to the new structure. The base isolation system decouples the building from the horizontal ground motion induced by earthquake, and offers very stiff vertical components to the base level of the superstructure in connection to substructure (foundation). It shifts the fundamental lateral period, dissipates the energy in damping, and reduces the amount of the lateral forces that transferred to the building, inter-story drift, and the floor acceleration.
\end{abstract}

The work deals with modelling and finite element analysis of a high damping rubber bearing in ANSYS 12.0. A displacement controlled transient analysis was done to analyse the behaviour of the isolator during earthquakes.

Keywords: Base isolation, High damping rubber, Transient analysis

\section{INTRODUCTION}

The use of seismic isolation for structures has been gaining worldwide acceptance as an approach to aseismic design. Many experimental and numerical studies are required on isolation pads to substantiate the adequacy of design and service conditions so that they can be used for isolation of structures.

A variety of base isolation devices including Laminated Rubber Bearing (LRB), frictional bearing etc. have been developed. Among the isolation systems that have gained acceptance for practical implementation, LRB isolation pads are most widely used. Full scale and reduced scale isolation devices have been developed and tested in countries like Italy, Japan, and USA. Many experimental and numerical studies are required on isolation pads to substantiate the adequacy of design and service conditions so that they can be used for isolation of structures. Fig.1 shows the behaviour of a base isolator.

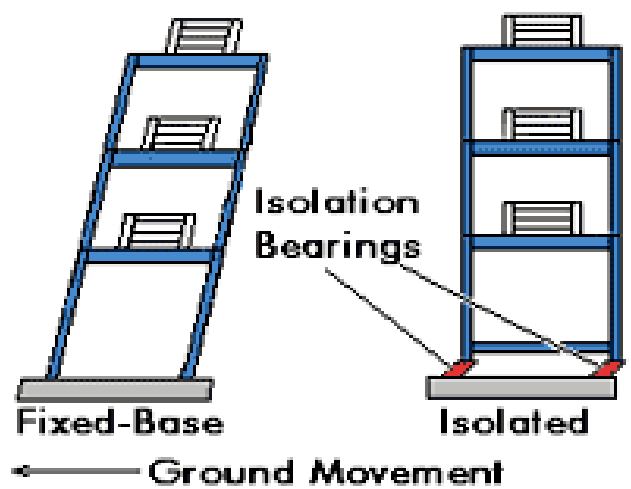

Fig -1: Comparison of a fixed base and base isolated building
This study tries to clarify the advantage of the base isolation technique with respect to buildings using laminated rubber bearings since only few researches were done into this area [1]. In this paper the numerical modelling of high damping rubber bearings (HDRB) is implemented using ANSYS 12.0. A three dimensional finite element model of the isolator is created and a non-linear static analysis is done. Based on the behaviour of the isolator, a parametric study is conducted by varying the material property.

\section{ANALYSIS MODEL}

The isolator is modelled through ANSYS 12.0, finite element software. The isolator is totally constraint at its base and only half of the isolator is modelled as it exhibits symmetric behaviour. To impose this symmetric behaviour on the half isolator all the point located on radius where it has been cut $(Z=0)$ have the rotation around $\mathrm{X}$ and $\mathrm{Y}$ and the translation along $\mathrm{Z}$ blocked. The nodes at the top surface are coupled in $\mathrm{Y}$ direction and $\mathrm{X}$ direction and vertical and horizontal loads are applied to the first node on the top surface.The dimensions of the model are given in the Table 1 .

Table -1: Dimensions of isolator

\begin{tabular}{|l|l|}
\hline Diameter & $1000 \mathrm{~mm}$ \\
\hline No. of rubber layers & 10 \\
\hline Thickness of rubber layer & $10 \mathrm{~mm}$ \\
\hline Thickness of steel plate & $4 \mathrm{~mm}$ \\
\hline Total height of isolator & $136 \mathrm{~mm}$ \\
\hline
\end{tabular}




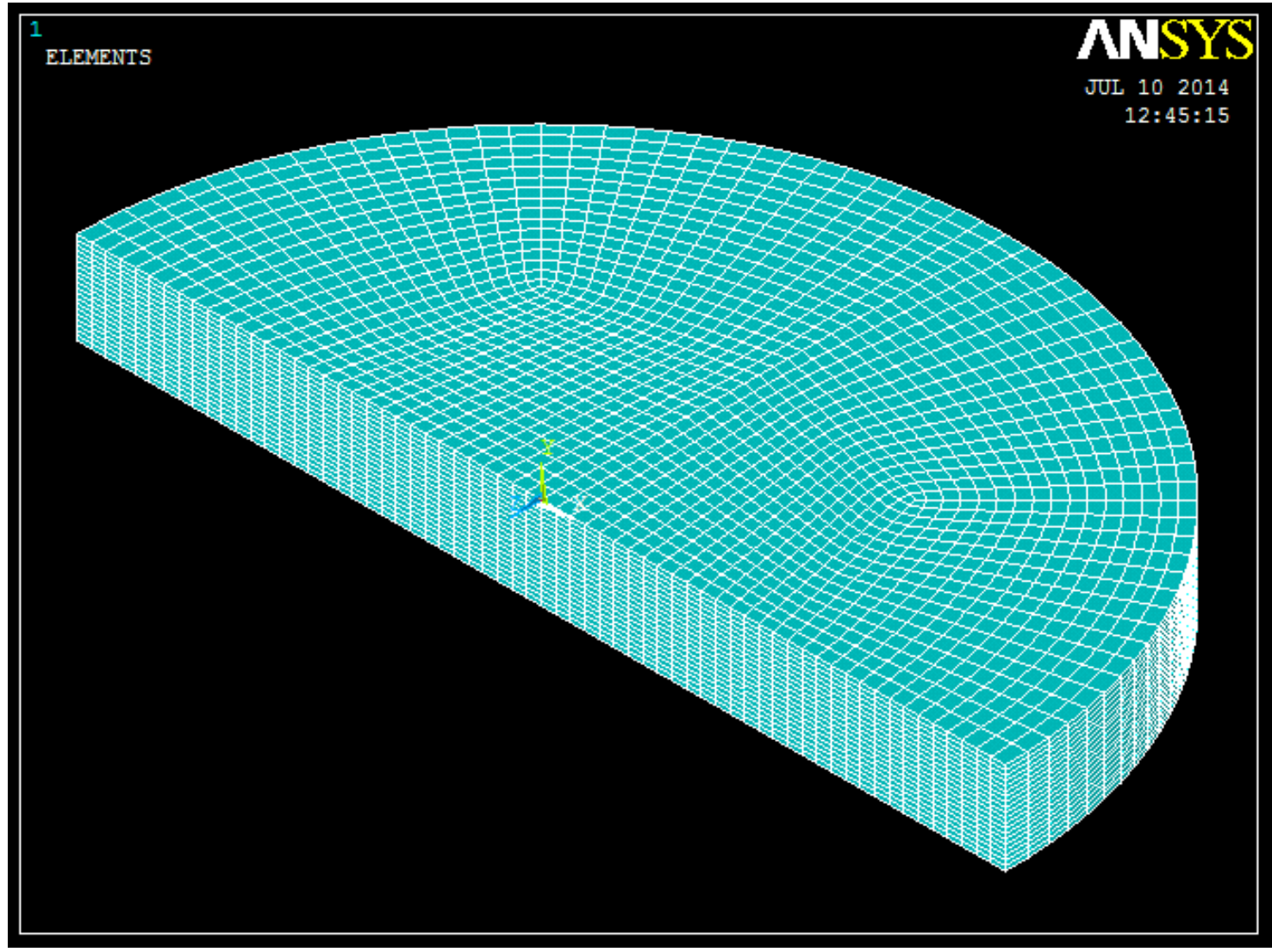

Fig -2: Isolator model

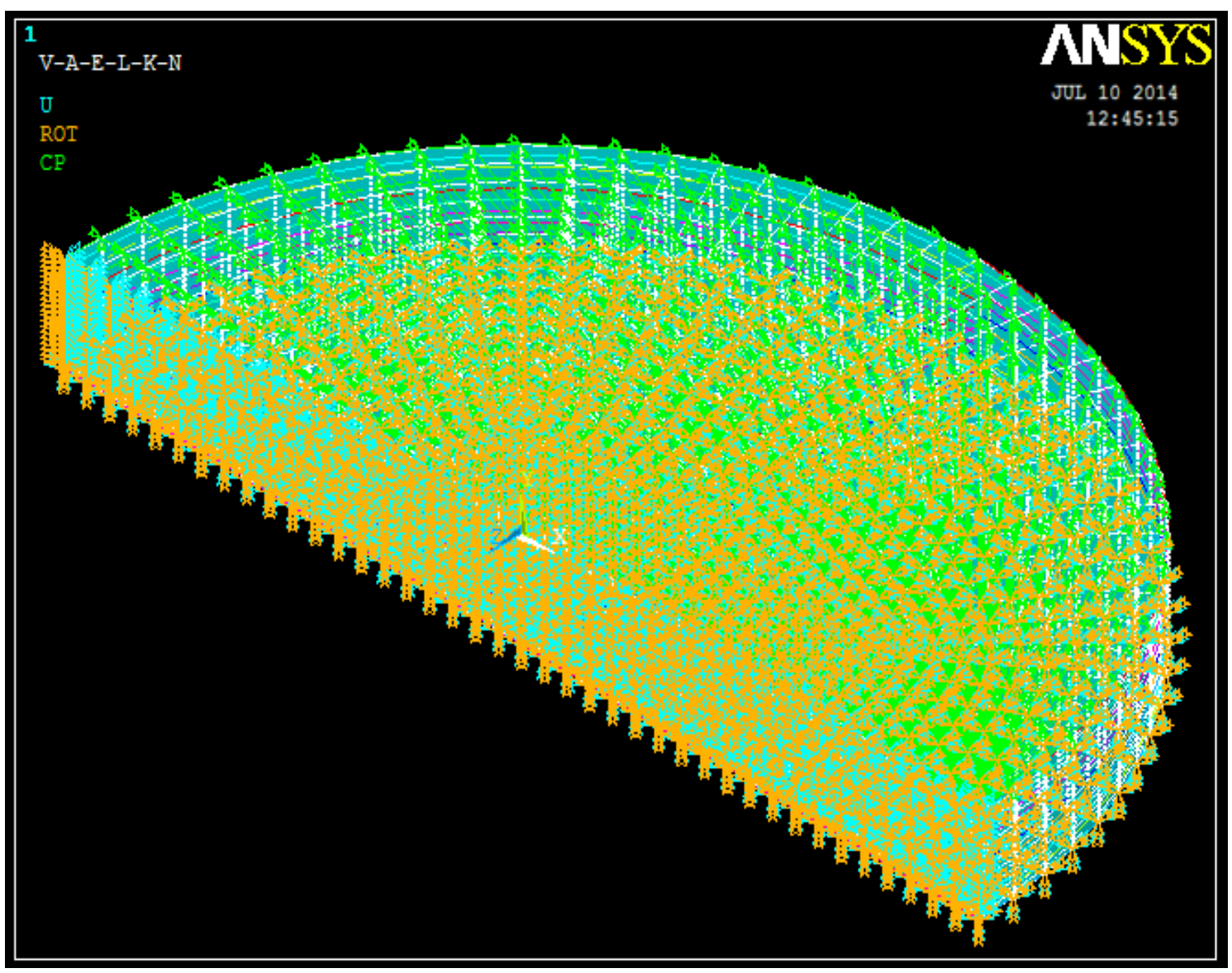

Fig -3: Model with boundary conditions 


\subsection{Material Property}

The isolation pads which undergo large deformation under seismic excitations thus exhibit strong nonlinear behaviour. Further the behaviour is complicated by the interaction of time dependence and sources of nonlinearities. Thus the numerical modelling need to take care of high material and geometrical nonlinearities The hyperelastic material is characterised by the existence of strain energy function $W$, measured per unit volume of reference state, which is a function of deformation gradient. Rubber material can be characterised by using different forms of strain energy density functions. Among reported materials models, ANSYS isotropic hyperelastic models are listed which are commonly adopted to reproduce a static loading path[2]:

- $\quad$ Neo-hookean, with 2 parameters;

- Mooney-Rivlin, with 2, 3, 5 or 9 parameters;

- $\quad$ Polynomial form, with $\mathrm{N} 2+\mathrm{N}$ parameters;

- $\quad$ Ogden, with $3 \mathrm{~N}$ parameters (3N-2 independent);

- $\quad$ Arruda-Boyce, with 3 parameters;

- $\quad$ Gent, with 3 parameters;

- $\quad$ Yeoh, with $2 \mathrm{~N}$ parameters;

- $\quad$ Ogden form, with $2 \mathrm{~N}$ parameters;

- Blatz-Ko, with 1 parameter;

- $\quad$ User-defined subroutine;

For the rubber model several form of the strain energy functions have been tested and the more accurate has been chosen (POLY-2P). The generic equation ( expressed in function of $\mathrm{W}$ ) is presented first. It has the following form:

$$
\begin{aligned}
& W=C_{10}\left(I_{1}-3\right)+C_{01}\left(I_{2}-3\right)+C_{20}\left(I_{1}-3\right)^{2}+C_{02}\left(I_{2}-3\right)^{2}+ \\
& C_{11}\left(I_{1}-3\right)\left(I_{2}-3\right)
\end{aligned}
$$

$\boldsymbol{C}_{10}, \boldsymbol{C}_{01}, \boldsymbol{C}_{20}, \boldsymbol{C}_{02}$ and $\boldsymbol{C}_{11}$ are the parameters, they depend on the material that has to be modeled and should be chosen to fit the material behaviour.The Polynomial 2-P function is used here and the material parameters were obtained as follows [3]:
$C_{01}=-0.05910$
$C_{20}=0.01609$
$C_{02}=1.103 \times 10^{-3}$

Steel is modeled as linearly elastic material with $\mathrm{E}=2 \times 10^{5}$ $\mathrm{MPa}$ and $v=0.3$.

\subsection{Modeling}

The elements used are, SOLID185 for the rubber layer and SHELL63 for the steel layer and MPC184 element is used as a connecting link.

First the rubber layer is created by extruding a circular area to the required thickness. The layer is then meshed using hexahedral mapped meshing and the number of elements in a layer is controlled using the dimensional parameter. Each layer of rubber has two element layers. The steel layer is created from a meshed area that has the thickness of a single layer. The rubber-steel interface has a frictionless bonding contact which is modelled using Multi-point constraint elements that transfers forces and moments. The coincident nodes at the interface are selected and rigid beam elements are created at these nodes. The cycle is repeated till the entire isolator is modelled.

\section{ANALYSIS}

The seismic analysis of the isolator is essential in order to analyse the behaviour of the bearing in the event of an earthquake. A displacement controlled transient analysis was done to study its behaviour. The N-S component of EL Centro earthquake (or 1940 Imperial valley earthquake) was used as the accelerogram data (Fig.4). The accelerogram data can be double integrated to get the displacement time history (Anil K Chopra, Dynamics of Structures). The displacement time history is used for the transient analysis and was done by applying the displacement at various instants as subsequent load steps with a time increment of 1 second with a total of 31 seconds (31 load steps).

$C_{10}=0.797$

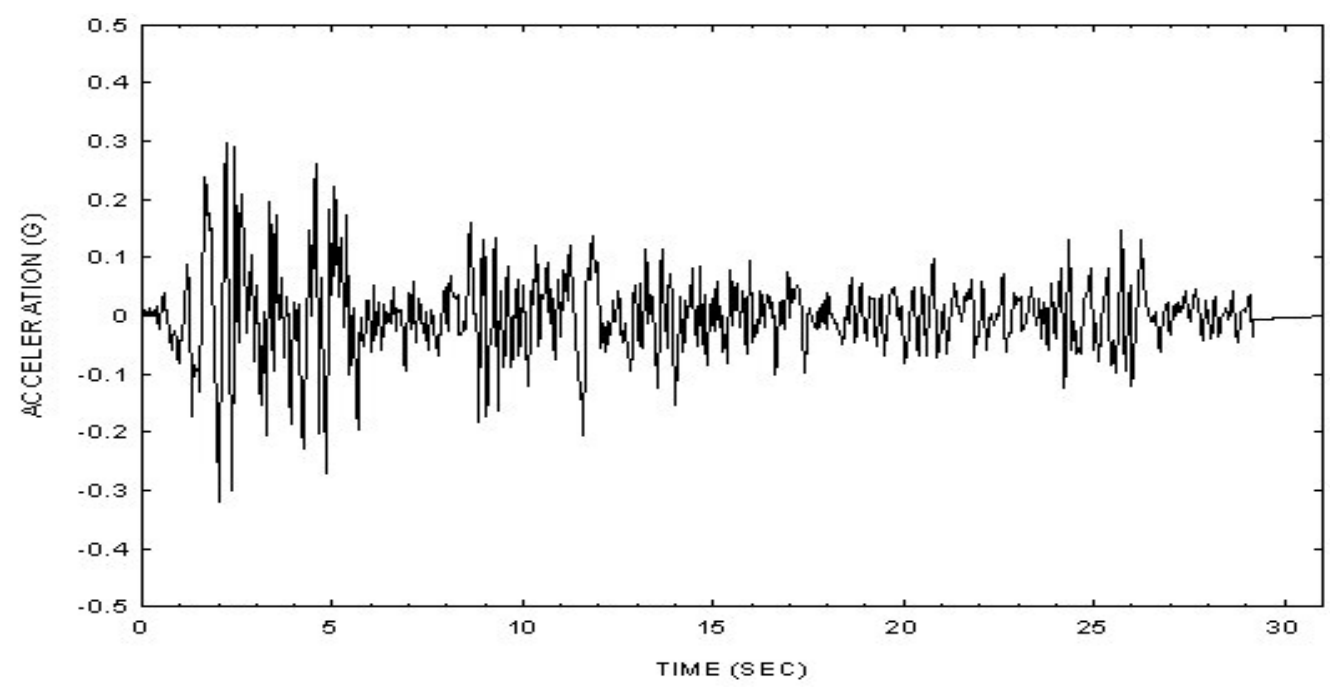

Fig -4: EL Centro Earthquake Accelerogram data 


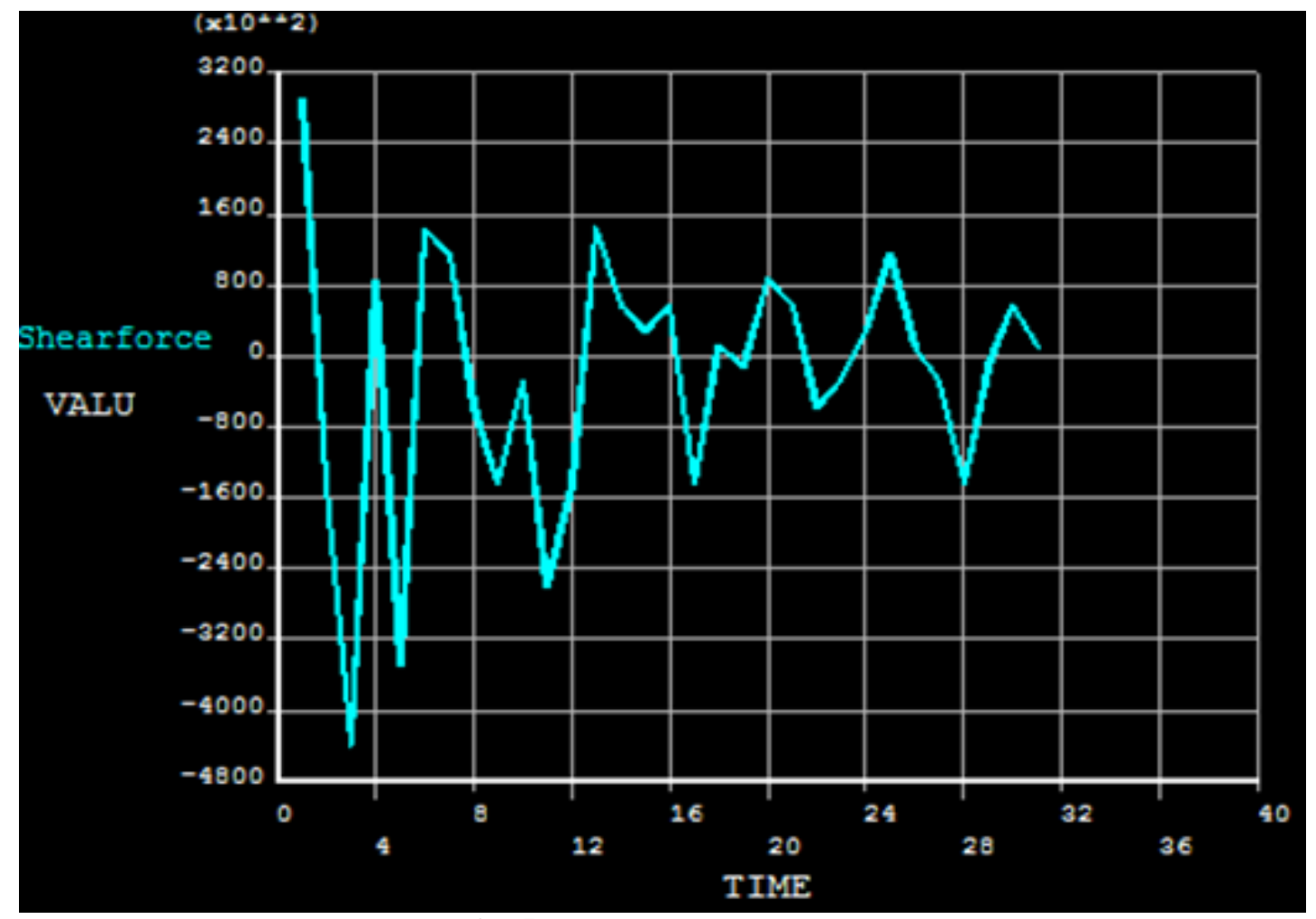

Fig -5: Shear force Vs Time plot

The variation of horizontal shear force, axial stress and shear stress with time is shown in Fig.5 to Fig.7. A maximum shear force of around $450 \mathrm{KN}$ is induced in the isolator.

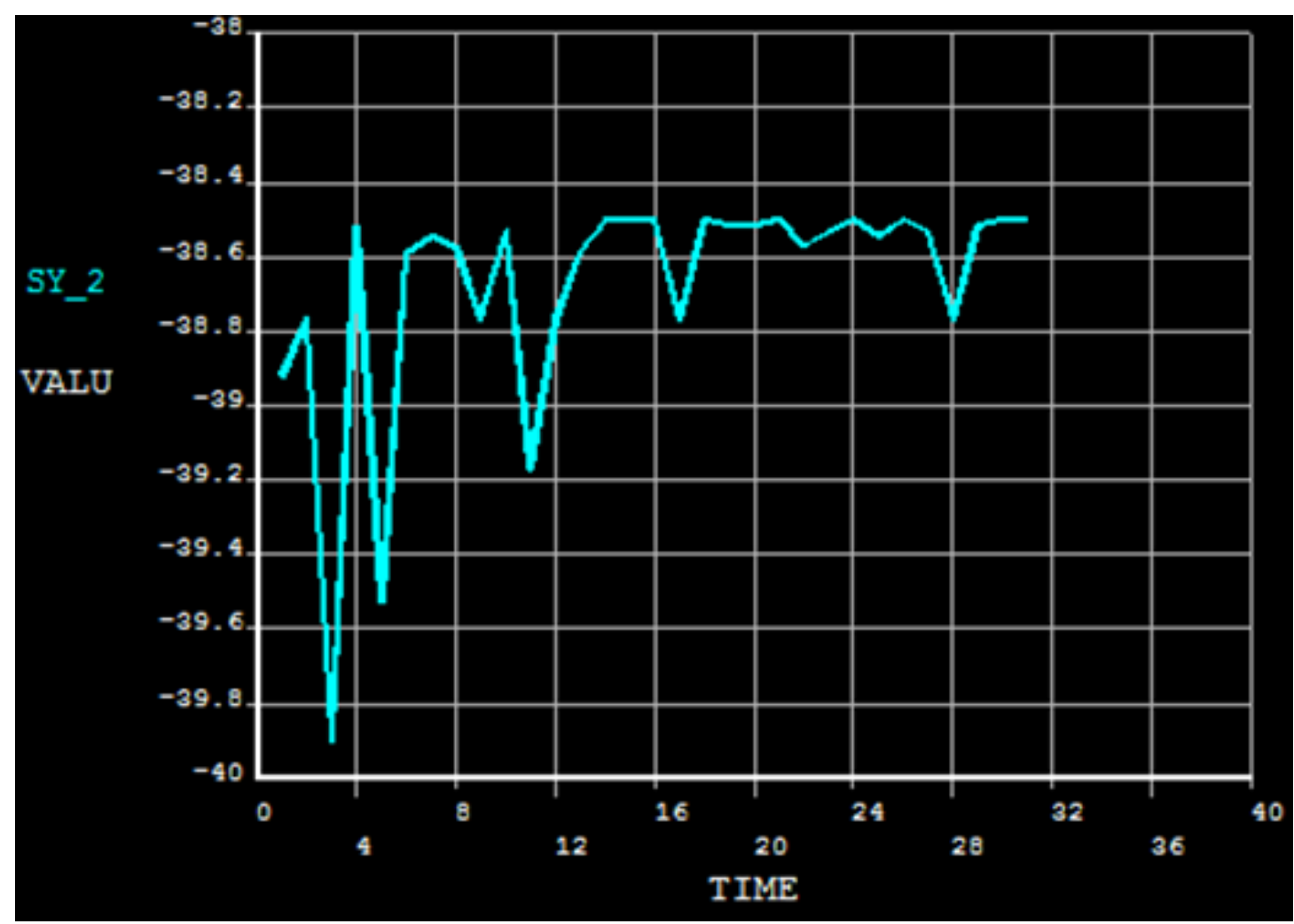

Fig -6: $\sigma_{\mathbf{y}}$ Vs Time plot 


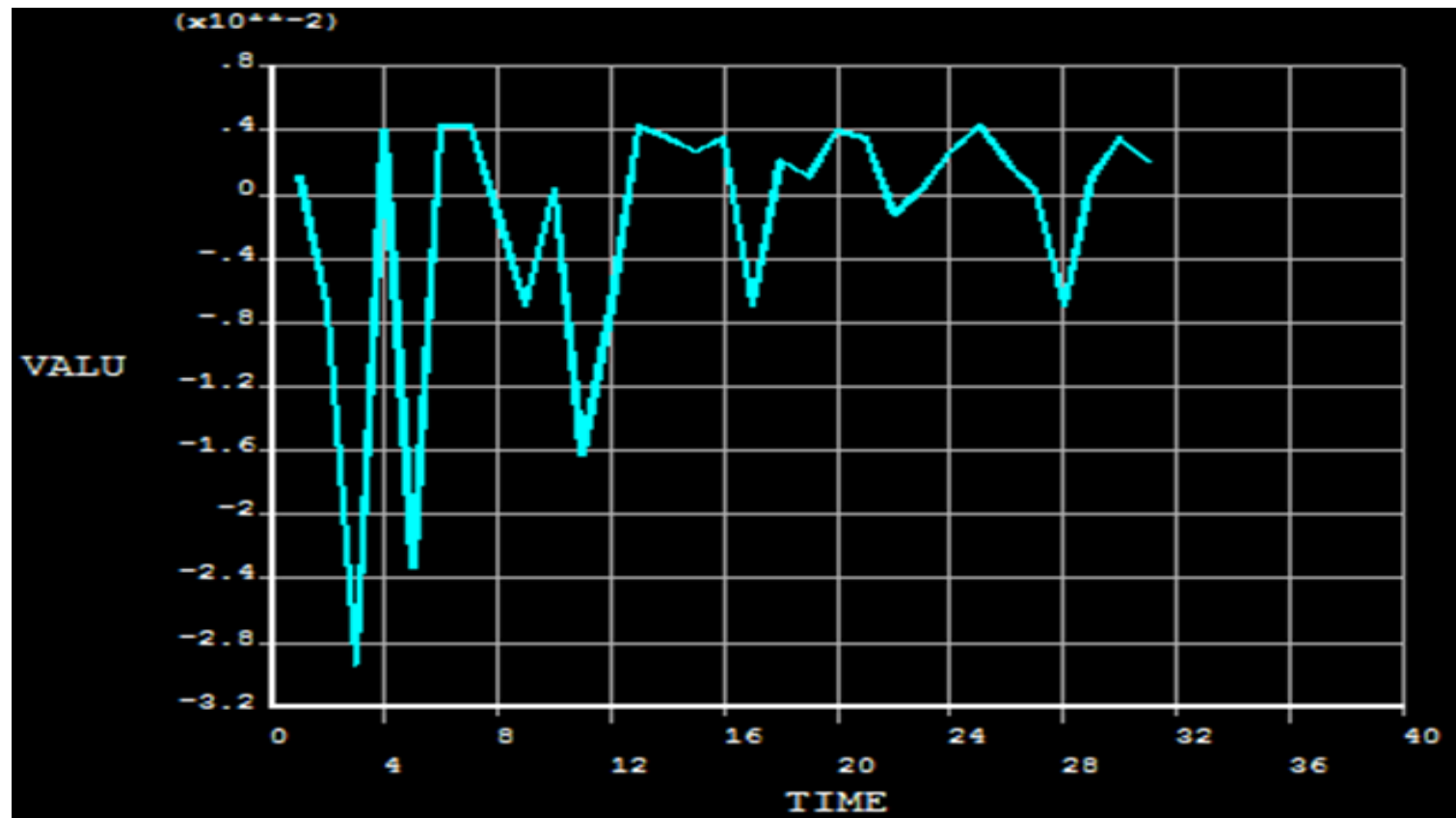

Fig -7: $\tau_{\mathrm{xy}}$ Vs Time plot

The permissible tensile stress in rubber can be defined as [4]:

$$
\begin{aligned}
\sigma_{\mathrm{y}} & =3 \mathrm{G} \\
& =3 \times 1.4 \\
& =4.2 \mathrm{MPa}
\end{aligned}
$$

Hence if the value of axial stress exceeds this permissible limit, it will lead to cavitation in the rubber layers and the bearing will lose its stability[5].

Fig. 8 to Fig.11 shows the deformed shape and stress values. It can be seen that the maximum axial tensile stress is $1.067 \mathrm{MPa}$ which is well within the permissible limit.Shear $\tau_{\mathrm{xz}}$ has maximum values at the interface of the steel and rubber layer. The shear stress $\tau_{\mathrm{xy}}$ has maximum values towards the right edge or the left edge depending on the direction of cyclic displacement which changes sign at every instant.

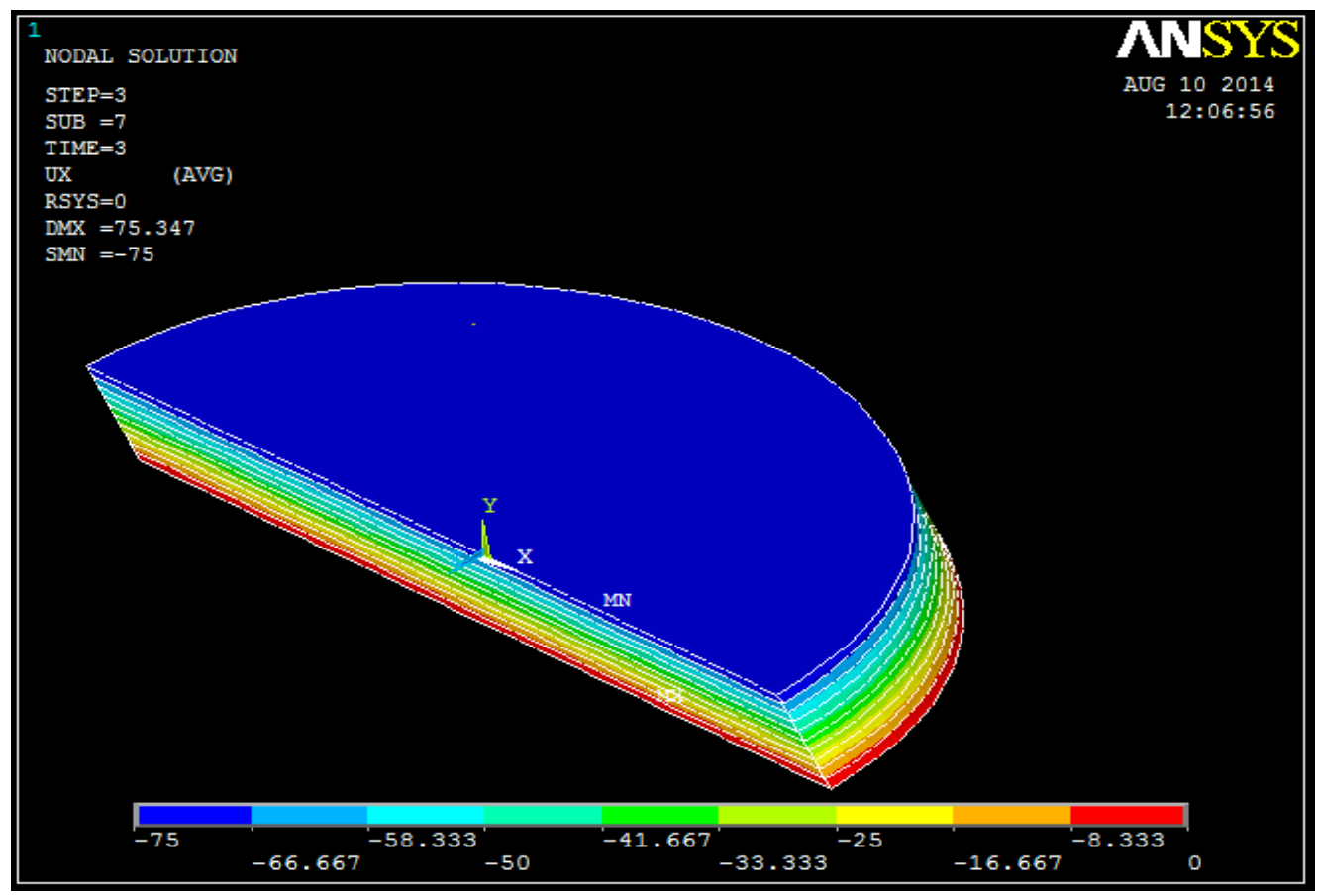

Fig -8: Deformed shape 


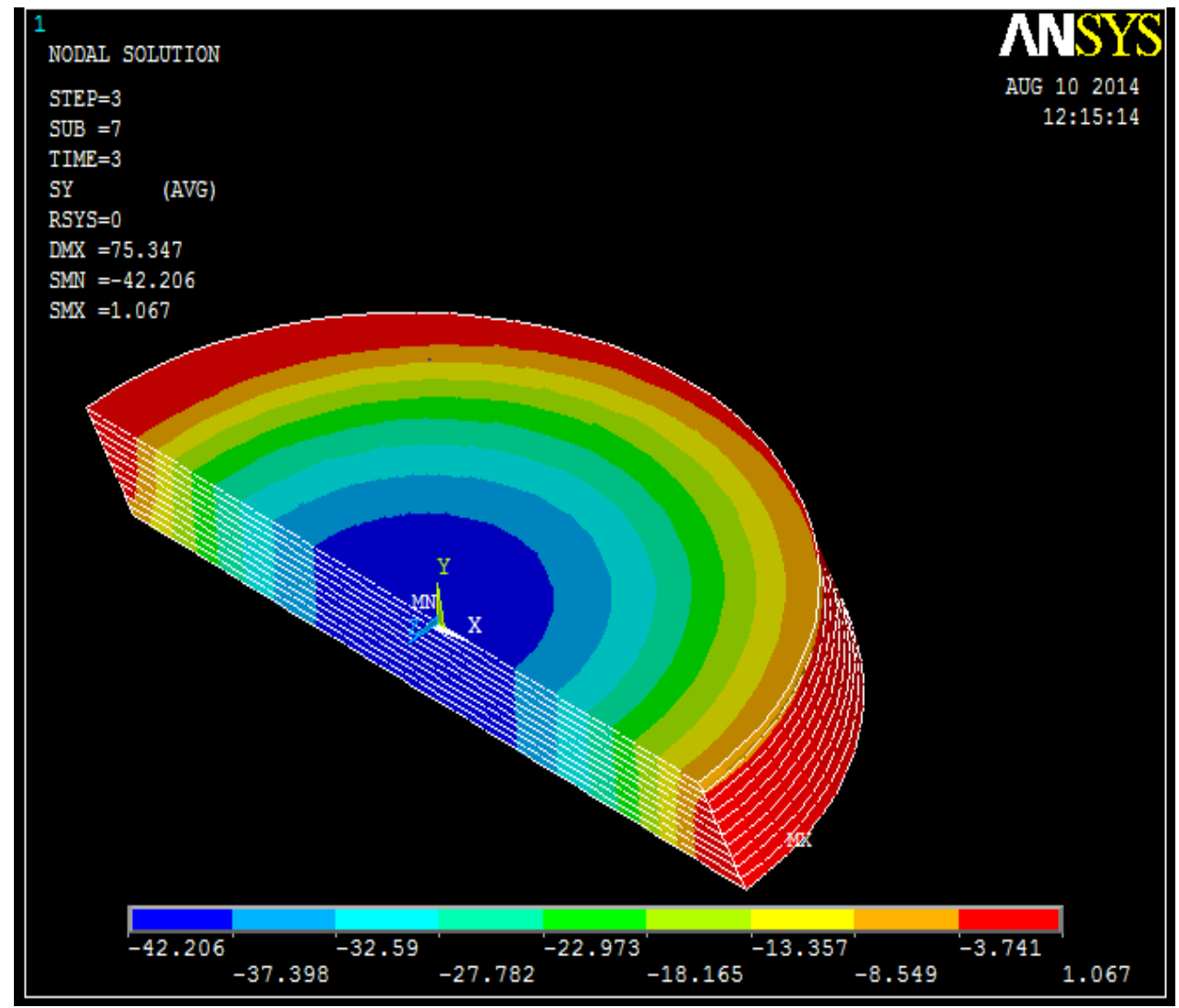

Fig -9: Axial stress $\sigma_{\mathrm{y}}$

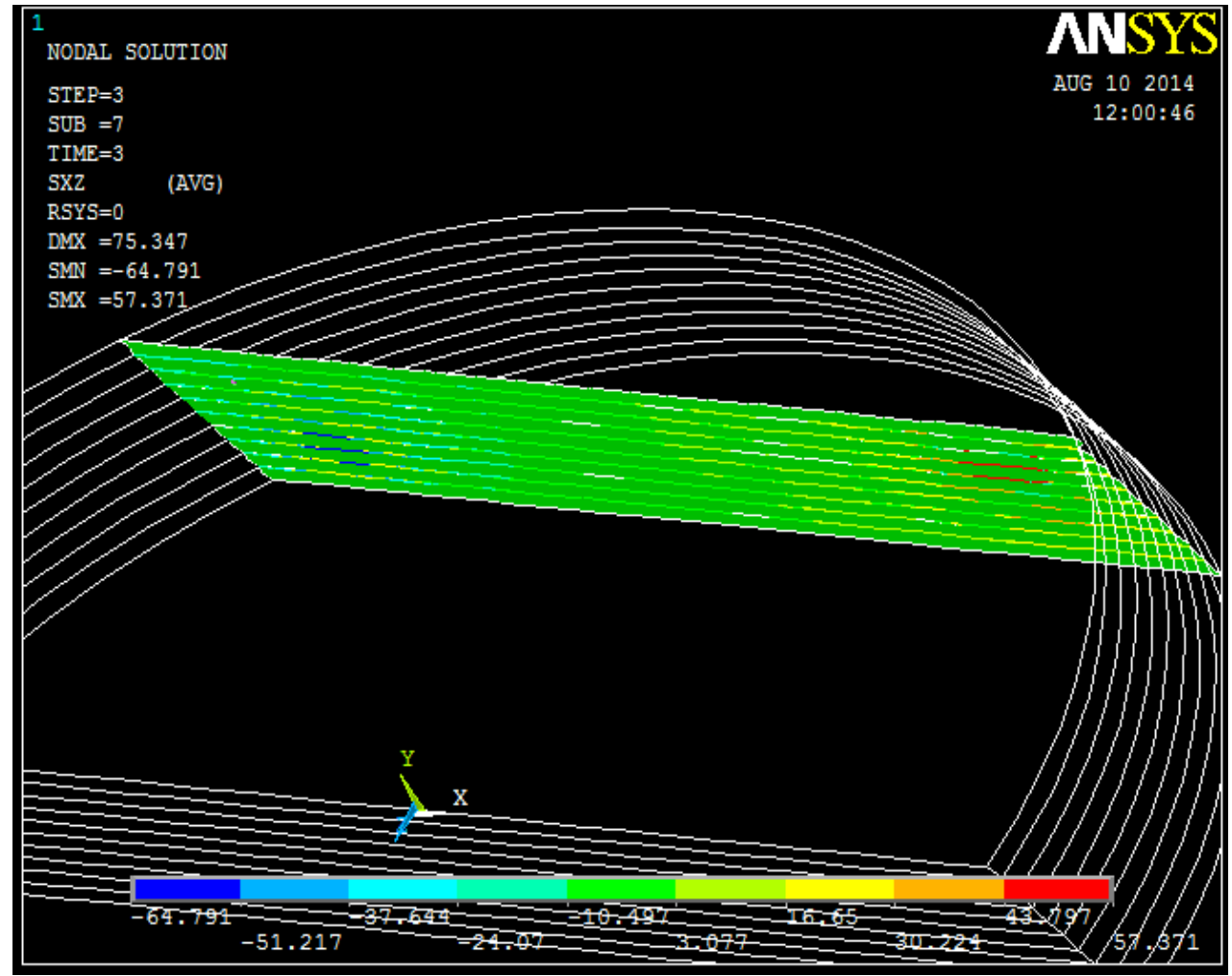

Fig -10: Shear stress $\tau_{\mathrm{xz}}$ 


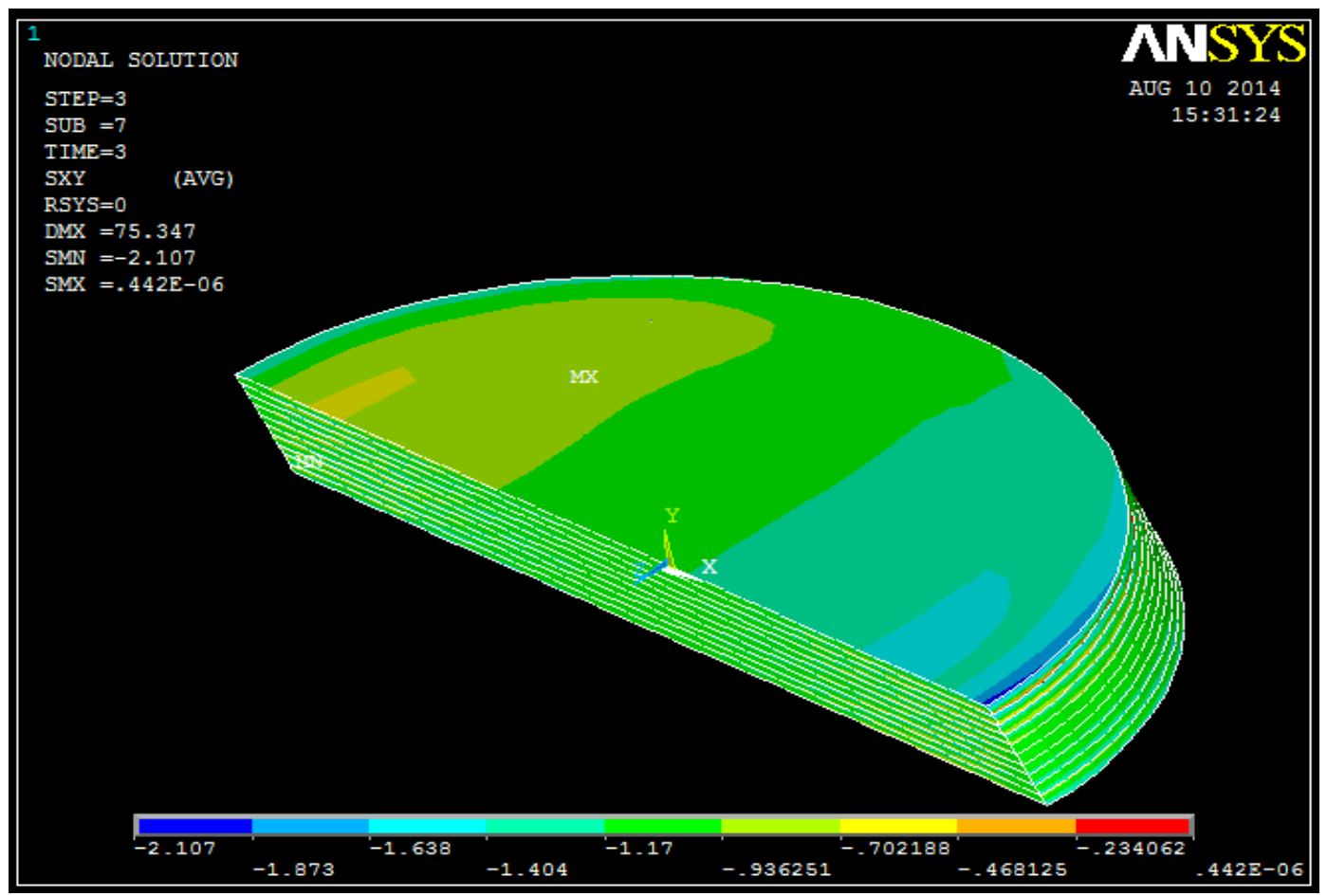

Fig -11: Shear stress $\tau_{\mathrm{xy}}$

\section{CONCLUSION}

The high damping rubber bearing was modeled and nonlinear finite element analysis was done using ANSYS 12.0. The main conclusions were:

- The maximum displacement that the isolator can undergo without losing its stability corresponds to $350 \%$ of shear strain or $350 \%$ of the thickness of rubber layer.

- However the isolator can take upto $400 \%$ shear strain but the tensile stress exceeds the permissible limit which can damage the bearing.

- The isolator can withstand cyclic displacements and can be used for accelerations of around $0.3 \mathrm{~g}$. The stresses induced were found to be within the permissible limit.

\section{REFERENCES}

[1]. S.B. Bhoje, P. Chellapandi, S. Chetal, R. Muralikrishna and T. Salvaraj, Comparison of computer simulated and observed force deformation characteristics of anti-seismic devices and isolated structures, Indira Gandhi Centre for Atomic Research, India, 1998.

[2]. Federico Perotti, Giorgio Bianchi, Davide C.M, Limit State Domain Of High Damping Rubber Bearings In Seismic Isolated Nuclear Power Plants, Politecnico Di Milano, 2011.

[3]. C. Constantinou, A. S. Whittaker, Y. Kalpakidis, D. M. Fenz and G. P. Warn, Performance of Seismic Isolation Hardware under Service and Seismic Loading, Technical Report MCEER-07, State University of New York, Buffalo, 2007.
[4]. Kelly, J.M and Takhirov, S.M, Analytical and Experimental Study of Fibre-Reinforced Elastomeric Isolator, PEERR Report, 2001.

[5]. Animesh Das, Anjan Dutta and S.K Deb, Modeling of Fiber-Reinforced Elastomeric Base Isolators, The $15^{\text {th }}$ World Conference on Earthquake Engineering, Lisboa, 2012. 